Figure. Mean PROMIS-29 T-scores at Baseline, W24, and W52 (Observed Data)

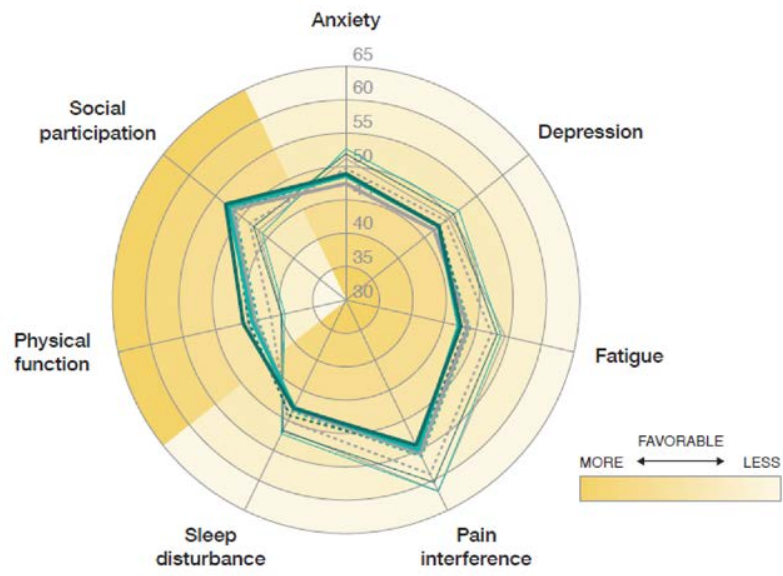

Baseline

Week 24

Week 52
GUS Q4W $(n=124)$

GUS Q8W ( $n=114)$ $\mathrm{PBO} \rightarrow \mathrm{GUS}$ Q4W $(\mathrm{n}=104)$

-Improvements are indicated by decreasing scores in anxiety, depression, tatigue, pain interference,

and sleep disturbance, and increasing scores in physical function and social participation.

Table 1. Mean Change and Effect Size of Change From Baseline in PROMIS-29 Domain Scores at W24 and W52 (Observed)

\begin{tabular}{|c|c|c|c|c|c|c|}
\hline & \multicolumn{6}{|c|}{ Mean Change From Baseline [Effect Size] } \\
\hline & \multicolumn{2}{|c|}{ GUS Q4W } & \multicolumn{2}{|c|}{ GUS Q8W } & \multirow{2}{*}{$\begin{array}{c}\begin{array}{c}\text { PBO } \\
\text { W0-24 }\end{array} \\
\text { W24 }\end{array}$} & \multirow{2}{*}{$\begin{array}{c}\text { GUS Q4W } \\
\text { W24-52 }\end{array}$} \\
\hline & W24 & W52 & W24 & W52 & & \\
\hline Anxiety & $-3.1[-0.3]$ & $-3.1[-0.3]$ & $-3.7[-0.4]$ & $-4.3[-0.5]$ & $-1.5[-0.2]$ & $-3.6[-0.4]$ \\
\hline Depression & $-2.7[-0.3]$ & $-3.0[-0.4]$ & $-4.0[-0.4]$ & $-4.0[-0.4]$ & $-0.6[-0.1]$ & $-2.5[-0.3]$ \\
\hline Fatigue & $-4.8[-0.5]$ & $-5.6[-0.6]$ & $-4.8[-0.5]$ & $-6.8[-0.7]$ & $-2.1[-0.2]$ & $-5.7[-0.6]$ \\
\hline Pain interference & $-5.4[-0.8]$ & $-6.2[-1.0]$ & $-5.8[-1.0]$ & $-7.0[-1.1]$ & $-2.8[-0.4]$ & $-6.3[-1.0]$ \\
\hline Physical function & $5.0[0.8]$ & $5.9[0.9]$ & $4.1[0.6]$ & $5.0[0.7]$ & $1.7[0.2]$ & $4.2[0.6]$ \\
\hline Sleep disturbance & $-2.5[-0.4]$ & $-3.9[-0.6]$ & $-3.8[-0.6]$ & $-4.4[-0.6]$ & $-1.5[-0.2]$ & $-3.3[-0.5]$ \\
\hline Social participation & $4.2[0.5]$ & $5.3[0.7]$ & $5.3[0.6]$ & $6.6[0.8]$ & $1.7[0.2]$ & $4.9[0.6]$ \\
\hline Pain intensity ${ }^{\star}$ & $-2.3[-1.2]$ & $-2.8[-1.5]$ & $-2.1[-1.1]$ & $-2.7[-1.4]$ & $-0.7[-0.4]$ & $-2.5[-1.3]$ \\
\hline
\end{tabular}

${ }^{*}$ Raw score; all other domains reported as T-score.

Disclosure of Interests: Ana-Maria Orbai Consultant of: Eli Lilly, Janssen, Novartis, Pfizer, UCB, Grant/research support from: Abbvie, Eli Lilly and Company, Celgene, Novartis, Janssen, Horizon, Laura C Coates Consultant of: AbbVie, Amgen, Biogen, Bristol Myers Squibb, Boehringer Ingelehim, Celgene, Domain, Eli Lilly, Gilead, Janssen, Medac, Novartis, Pfizer and UCB, Grant/ research support from: AbbVie, Amgen, Celgene, Eli Lilly, Gilead, Novartis, Pfizer, Atul Deodhar Speakers bureau: AbbVie, Eli Lilly, Janssen, Novartis, Pfizer, and UCB, Consultant of: AbbVie, Amgen, Boehringer Ingelheim, Bristol Myers Squibb, Celgene, Eli Lilly, Galapagos, GSK, Janssen, Novartis, Pfizer, and UCB, Grant/research support from: AbbVie, Eli Lilly, GSK, Novartis, Pfizer, and UCB, Philip Helliwell Consultant of: Galapagos, Janssen, and Novartis, Grant/research support from: Abbvie, Janssen, and Pfizer, Christopher T. Ritchlin Consultant of: AbbVie, Amgen, Gilead, Janssen, Lilly, Novartis, Pfizer, UCB Pharma, Grant/ research support from: AbbVie, Amgen, UCB Pharma, Alexa Kollmeier Shareholder of: Johnson \& Johnson, of which Janssen Research \& Development, LLC is a wholly owned subsidiary, Employee of: Janssen Research \& Development, LLC, Elizabeth C Hsia Shareholder of: Johnson \& Johnson, of which Janssen Research \& Development, LLC is a wholly owned subsidiary, Employee of: Janssen Research \& Development, LLC, Xie L Xu Shareholder of: Johnson \& Johnson, of which Janssen Research \& Development is a wholly owned subsidiary, Employee of: Janssen Research \& Development, LLC, Shihong Sheng Shareholder of: Johnson \& Johnson, of which Janssen Research \& Development, LLC is a wholly owned subsidiary, Employee of: Janssen Research \& Development, LLC, Yusang Jiang Employee of: Cytel, Inc., providing statistical support (funded by Janssen), Yan Liu Shareholder of: Johnson \& Johnson, of which Janssen Research \& Development, LLC is a wholly owned subsidiary, Employee of: Janssen Research \& Development, LLC, Chenglong Han Shareholder of: Johnson \& Johnson, of which Janssen Research \& Development, LLC is a wholly owned subsidiary, Employee of: Janssen Research \& Development, LLC. DOI: 10.1136/annrheumdis-2021-eular.471

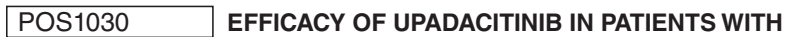 PSORIATIC ARTHRITIS STRATIFIED BY BASELINE SKIN SEVERITY: A SUBGROUP ANALYSIS OF TWO PHASE III TRIALS}

J. F. Merola ${ }^{1,2}$, P. Richette ${ }^{3}$, E. Lubrano ${ }^{4}$, E. Drescher ${ }^{5}$, L. Soto ${ }^{6}$, C. Lovan ${ }^{7}$, K. Kato ${ }^{7}$, R. Lippe ${ }^{8}$, M. Lane ${ }^{7}$, M. Kishimoto ${ }^{9} .{ }^{1}$ Brigham and Women's Hospital, Division of Rheumatology, Immunology and Allergy, Boston, United States of America; ${ }^{2}$ Harvard Medical School, Division of Rheumatology, Boston, United States of America; ${ }^{3}$ Hopital Lariboisiere Centre Viggo Petersen and Inserm UMR1132 Bioscar, Universite Paris Diderot UFR de Medecine, Service de Rhumatologie, Paris, France; ${ }^{4}$ University of Molise, Department of Medicine and Health Sciences Vincenzo Tiberio, Campobasso, Italy; ${ }^{5}$ Veszprém Csolnoky Ferenc County Hospital, Veszprém, Hungary; ${ }^{6}$ Universidad de Chile, Facultad de Medicina, Santiago, Chile; ${ }^{7}$ AbbVie, Immunology, North Chicago, United States of America; ${ }^{8} \mathrm{AbbVie}$ Deutschland GmbH \& Co. KG, Immunology, Wiesbaden, Germany; ${ }^{9}$ Kyorin University School of Medicine, Department of Nephrology and Rheumatology, Tokyo, Japan

Background: In the SELECT-PsA 1 and 2 clinical trials, upadacitinib (UPA) demonstrated efficacy and safety in patients (pts) with active psoriatic arthritis (PsA). ${ }^{1,2} \mathrm{PsA}$ is associated with varying degrees of psoriatic symptoms; however, the impact of skin severity on treatment outcomes is not well understood.

Objectives: This post-hoc analysis assessed the effects of baseline skin severity on UPA efficacy.

Methods: SELECT-PSA 1 and SELECT-PsA 2 enrolled pts with PsA and prior inadequate response (IR) or intolerance to $\geq 1$ non-biologic disease-modifying antirheumatic drug (DMARD) ${ }^{1}$ or $\geq 1$ biologic DMARD ${ }^{2}$, respectively. In both trials, pts received once daily UPA $15 \mathrm{mg}$ or UPA $30 \mathrm{mg}$ or placebo (switched at Wk 24 to either UPA $15 \mathrm{mg}$ or $30 \mathrm{mg}$ ); SELECT-PsA 1 also included the active comparator adalimumab (ADA). Only continuous UPA $15 \mathrm{mg}$ and ADA are presented here. In this analysis, pts were divided into subgroups based on the extent of psoriasis at baseline (body surface area $[B S A]$ of $\geq 3 \%-<10 \%$ or BSA $\geq 10 \%$ ); efficacy endpoints were analyzed at Wk 56 . Results for binary endpoints are based on non-responder imputation; continuous endpoints are based on mixed model repeated measures analysis with as-observed data.

Results: In the UPA $15 \mathrm{mg}$ and ADA groups, respectively, 32\% (138/429) and $31 \%(132 / 429)$ of pts had a BSA $\geq 3-<10 \%$ at baseline in SELECT-PSA $1 ; 18 \%$ (76/429) in each treatment group had a BSA $\geq 10 \%$. In SELECT-PsA $2,38 \%$ (80/211) had a BSA $\geq 3-<10 \%$ and $24 \%(50 / 211)$ had a BSA $\geq 10 \%$ at baseline in the UPA $15 \mathrm{mg}$ group. Across pt populations (non-biologic DMARD-IR and biologic DMARD-IR), generally consistent results were observed between patients in both skin severity subgroups (Figure 1). In non-biologic DMARD-IR pts, a numerically greater proportion of UPA $15 \mathrm{mg}$ pts with lower skin involvement compared with higher skin involvement achieved PASI100 and PASI 1 , two more stringent

Figure. Efficacy Outcomes at Week $\mathbf{5 6}$ Stratified by the Severity of Skin Involvement at Baseline SELECT-PSA 1 - non-biologic DMARD-IR patients
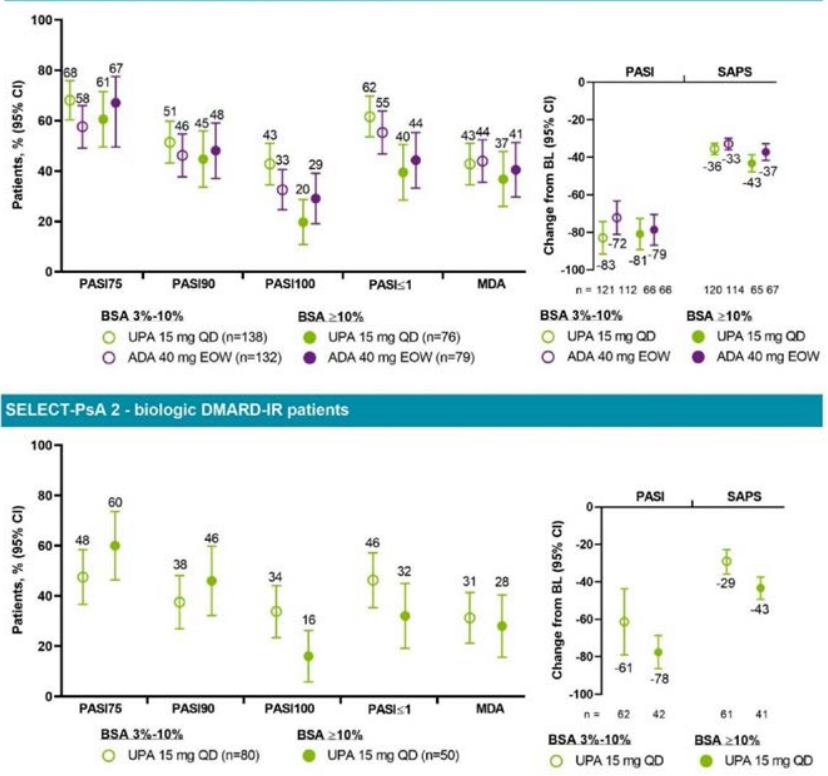

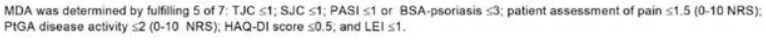
ADA, adalimumab; BL, baseline; BSA, body surtace area; CI, confdence interval; EOW, every other week; HAQ-DI, Health

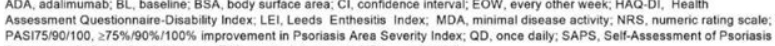


Table 1. Additional Efficacy Outcomes at Week 56 Stratified by Severity of Skin Involvement at Baseline

\begin{tabular}{|c|c|c|}
\hline \multicolumn{3}{|c|}{ SELECT-PSA 1} \\
\hline $\mathrm{n} / \mathrm{N}(\%)[95 \% \mathrm{Cl}]$ & UPA $15 \mathrm{mg}$ & ADA \\
\hline \multicolumn{3}{|l|}{$\begin{array}{l}\text { sIGA 0/1 w/at least } 2 \text { point } \\
\text { improvement from } \mathrm{BL}^{\mathrm{a}}\end{array}$} \\
\hline$\geq 3 \%-<10 \%$ & $71 / 128(55.5)[46.9,64.1]$ & $53 / 124(42.7)[34.0,51.4]$ \\
\hline$\geq 10 \%$ & $29 / 76(38.2)[27.2,49.1]$ & $33 / 77(42.9)[31.8,53.9]$ \\
\hline \multicolumn{3}{|l|}{$\mathrm{MDA}+$ skin $^{\mathrm{b}}$} \\
\hline$\geq 3 \%-<10 \%$ & $58 / 138(42.0)[33.8,50.3]$ & $56 / 132(42.4)[34.0,50.9]$ \\
\hline$\geq 10 \%$ & $19 / 76(25.0)[15.3,34.7]$ & $28 / 79(35.4)[24.9,46.0]$ \\
\hline \multicolumn{3}{|l|}{ SELECT-PSA 2} \\
\hline $\mathrm{n} / \mathrm{N}(\%)[95 \% \mathrm{Cl}]$ & UPA $15 \mathrm{mg}$ & \\
\hline \multicolumn{3}{|l|}{$\begin{array}{l}\text { sIGA 0/1 w/at least } 2 \text { point } \\
\text { improvement from } \mathrm{BL}^{\mathrm{a}}\end{array}$} \\
\hline$\geq 3 \%-<10 \%$ & $24 / 71$ (33.8) [22.8, 44.8] & \\
\hline $\begin{array}{l}\geq 10 \% \\
\text { MDA }+ \text { skin }^{b}\end{array}$ & $18 / 50$ (36.0) $[22.7,49.3]$ & \\
\hline$\geq 3 \%-<10 \%$ & $22 / 80(27.5)[17.7,37.3]$ & \\
\hline$\geq 10 \%$ & $9 / 50(18.0)[7.4,28.6]$ & \\
\hline
\end{tabular}

a defined as achieving an sIGA score of 0 or 1 and at least a 2 point improvement from $\mathrm{BL}$, evaluated in pts with $B L$ sIGA $\geq 2$.

${ }^{\mathrm{b}}$ defined as achieving 5 of the 7 criteria, with PASI $\leq 1$ or BSA-psoriasis $\leq 3$ as a required component.

ADA, adalimumab; $\mathrm{BL}$, baseline; $\mathrm{Cl}$, confidence interval; MDA, minimal disease activity; sIGA, Static Investigator Global Assessment of psoriasis; UPA, upadacitinib

skin endpoints. The achievement of MDA was generally consistent across skin severity subgroups; when pts were required to achieve the skin component of MDA, results were numerically better in the $\geq 3-<10 \%$ skin severity group (Table 1 ). In non-biologic DMARD-IR pts, results were similar between UPA $15 \mathrm{mg}$ and ADA. Conclusion: UPA is a viable treatment option for pts with active PsA regardless of the extent of psoriasis at baseline. Although these results are of interest and hypothesis-generating, they should be interpreted with caution due to low sample size. REFERENCES:

[1] Mclnnes IB et al. Ann Rheum Dis, 2020; 79:12

[2] Mease PJetal.Ann Rheum Dis, 2020; doi:10.1136/annrheumdis-2020-218870 Acknowledgements: AbbVie and the authors thank the patients, study sites, and investigators who participated in this clinical trial. AbbVie, Inc was the study sponsor, contributed to study design, data collection, analysis \& interpretation, and to writing, reviewing, and approval of final version. No honoraria or payments were made for authorship. Medical writing support was provided by Ramona Vladea, PhD and Jamie Urbanik, PharmD both of AbbVie Inc.

Disclosure of Interests: Joseph F. Merola Consultant of: Merck, Bristol-Myers Squibb, AbbVie, Dermavant, Eli Lilly, Novartis, Janssen, UCB, Celgene, Sanofi, Regeneron, Arena, Sun Pharma, Biogen, Pfizer, EMD Sorono, Avotres and Leo Pharma, Pascal Richette Consultant of: AbbVie, Biogen, Janssen, BMS, Roche, Pfizer, Amgen, Sanofi-Aventis, UCB, Lilly, Novartis, and Celgene, Ennio Lubrano Speakers bureau: AbbVie, Celgene, Janssen, MSD, Novartis, and Pfizer, Consultant of: AbbVie, Celgene, Janssen, MSD, Novartis, and Pfizer, Grant/research support from: AbbVie, Celgene, Janssen, MSD, Novartis, and Pfizer, Edit Drescher: None declared, Lilian Soto: None declared, Charles Lovan Shareholder of: AbbVie, Employee of: AbbVie, Koji Kato Shareholder of:AbbVie, Employee of: AbbVie, Ralph Lippe Shareholder of: AbbVie, Employee of: AbbVie, Michael Lane Shareholder of: AbbVie, Employee of: AbbVie, Mitsumasa Kishimoto Consultant of: AbbVie, Amgen-Astellas BioPharma, Asahi-Kasei Pharma, Astellas, Ayumi Pharma, BMS, Celgene, Chugai, Daiichi-Sankyo, Eisai, Eli Lilly, Gilead, Janssen, Kyowa Kirin, Novartis, Ono Pharma, Pfizer, Tanabe-Mitsubishi, Teijin Pharma, and UCB Pharma. DOI: 10.1136/annrheumdis-2021-eular.536

\section{POS1031 LOW INCIDENCE OF GASTROINTESTINAL-RELATED AND OVERALL SERIOUS ADVERSE EVENTS AMONG GUSELKUMAB-TREATED PATIENTS: POOLED ANALYSES OF VOYAGE 1 \& 2 AND DISCOVER 1 \& 2 THROUGH 1-YEAR}

P. J. Mease ${ }^{1}$, P. Foley ${ }^{2}$, K. Reich ${ }^{3}$, J. Bagel ${ }^{4}$, M. Lebwohl ${ }^{5}$, Y. W. Yang ${ }^{6}$, M. Shawi ${ }^{6}$

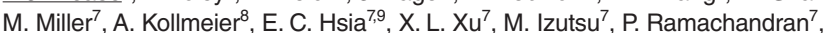
S. Sheng ${ }^{10}$, Y. You ${ }^{10}$, P. Helliwell ${ }^{11}$, W. H. Boehncke ${ }^{12} .{ }^{1}$ Swedish Medical Centerl Providence St. Joseph Health, University of Washington, Rheumatology Research, Seattle, United States of America; ${ }^{2}$ The University of Melbourne, St.Vincent's Hospital Melbourne and Probity Medical Research, Skin Health Institute, Department of Medicine, Carlton, Australia; ${ }^{3}$ University Medical Center Hamburg-Eppendorf Translational Research in Inflammatory Skin Diseases, Institute for Health Services Research in Dermatology and Nursing, Hamburg, Germany; ${ }^{4}$ Psoriasis Treatment Center of Central New Jersey, Department of Dermatology, East Windsor, United States of America; ${ }^{5}$ Icahn School of Medicine at Mount Sinai, Department of Dermatology, New York, United States of America; ${ }^{6}$ Janssen Global Services, LLC, Immunology, Horsham, United States of America;
${ }^{7}$ Janssen Research \& Development, LLC, Immunology, Spring House, United States of America; ${ }^{8} \mathrm{Janssen}$ Research \& Development, LLC, Immunology, San Diego, United States of America; ${ }^{9}$ University of Pennsylvania Health System, Rheumatology, Philadelphia, United States of America; ${ }^{10}$ Janssen Research \& Development, LLC, Biostatistics, Spring House, United States of America; "University of Leeds, Leeds Institute of Rheumatic and Musculoskeletal Medicine, Leeds, United Kingdom; ${ }^{12}$ Geneva University Hospitals, Department of Dermatology, Geneva, Switzerland

Background: Guselkumab (GUS), a human monoclonal antibody that specifically binds to the p19-subunit of interleukin (IL)-23, demonstrated efficacy in the Phase 3 VOYAGE $1 \& 2$ trials of patients (pts) with moderate to severe plaque psoriasis $(\mathrm{PsO})^{1,2}$ and in the DISCOVER 1\&2 trials of pts with active psoriatic arthritis (PsA) ${ }^{3,4}$ IL-17 inhibitors used to treat PsO and PsA have been associated with exacerbation or new onset of inflammatory bowel disease (IBD) (e.g. Crohn's disease or ulcerative colitis). ${ }^{5}$

Objectives: Evaluate the incidence of gastrointestinal (GI)-related and overal serious adverse events (SAEs) from pooled safety data through 1-year of GUS $100 \mathrm{mg}$ treatment from the VOYAGE $1 \& 2$ and DISCOVER $1 \& 2$ trials

Methods: Using pooled safety data from the VOYAGE $1 \& 2$ PsO trials and DISCOVER 1\&2 PsA trials, SAEs related to GI disorders were identified using the Medical Dictionary for Regulatory Activities (MedDRA) system-organ class "G disorders." Pts with a previous history of IBD were not excluded in these trials medical history of IBD was collected at baseline in DISCOVER 1\&2. Rates of overall SAEs and GI-related SAEs were calculated as the number of SAEs per 100 pt-years (PY) of follow-up (95\% confidence intervals). Data are presented for the placebo (PBO)-controlled period (Weeks 0-16 for VOYAGE 1\&2; Weeks 0-24 for DISCOVER 1\&2) and through 1-year (defined as through Week 48 for VOYAGE 1\&2; through Week 60 for DISCOVER 1, and through Week 52 fo DISCOVER 2). Events of uveitis and opportunistic infections were also analyzed. Results: Through the PBO-controlled period, the overall rates of Gl-related SAEs per 100 PY for pooled VOYAGE $1 \& 2$ were: PBO $0.78(0.02,4.34)$, GUS q8w 0 ; and for pooled DISCOVER 1\&2: PBO 0.58 (0.01, 3.23), GUS q8w 0.58 (0.01, 3.21), GUS q4w 0. The Gl-related SAEs included: gastrointestinal hemorrhage (PBO; $n=1$ ) for pooled VOYAGE 1\&2; and inflammatory bowel disease $(\mathrm{PBO} ; n=1)$ and mechanical ileus (GUS q8w; $n=1$ ) for pooled DISCOVER 1\&2. Through 1-year, the overall rates of Gl-related SAEs for pooled VOYAGE $1 \& 2$ were: Combined GUS group (GUS q8w and PBO $\rightarrow$ GUS groups) 0.51 (0.17, 1.20); and for pooled DISCOVER 1\&2: GUS q8w $0.52(0.06,1.88)$, GUS q4w 0, Combined GUS group (GUS q8w, GUS q4w, and PBO $\rightarrow$ GUS groups) $0.21(0.02,0.74)$. The Gl-related SAEs in the Combined GUS group for pooled VOYAGE 1\&2 included: gastritis, hemorrhoids, inguinal hernia, pancreatitis, and umbilical hernia $(0.10 / 100 \mathrm{PY}[0.00,0.57] ; n=1$ for each); and in the Combined GUS group for pooled DISCOVER 1\&2: mechanical ileus and pancreatitis chronic $(0.10 / 100 P Y[0.00,0.57] ; n=1$ for each). Overall, no cases of exacerbation or new onset of IBD were reported in GUS-treated pts, including 2 pts with a prior history of IBD in DISCOVER 1\&2 (total PY of follow-up for the Combined GUS groups in VOYAGE and DISCOVER were 974 and 973 , respectively). Through the PBO-controlled period, rates of overall SAEs for GUS-treated pts were comparable to PBO-pts and SAE rates remained low through 1-year of follow-up in the VOYAGE $1 \& 2$ and DISCOVER $1 \& 2$ trials. There were no reported cases of uveitis, opportunistic infections, or tuberculosis in GUS-treated pts through 1-year.

Conclusion: Through 1-year of follow-up with GUS treatment in pooled VOY AGE $1 \& 2$ and DISCOVER 1\&2, GI-related SAE rates were low. There were no reported cases of uveitis, opportunistic infections, or new onset/exacerbation of IBD in GUS-treated pts. No new safety concerns were identified through 1-year. REFERENCES:

[1] Blauvelt A., et al. J Am Acad Dermatol. 2017;76:405-17.

[2] Reich K., et al. J Am Acad Dermatol. 2017;76:418-31.

[3] Deodhar A., et al. Lancet. 2020;395:1115-25.

[4] Mease P.J., et al. Lancet. 2020; 395:1126-36.

[5] Hohenberger M., et al. J Dermatolog Treat. 2018;29:13-8.

Disclosure of Interests: Philip J Mease Consultant of: AbbVie, Amgen, Boehringer Ingelheim, Bristol Myers Squibb, Eli Lilly, Galapagos, Gilead, GlaxoSmithKline, Janssen, Novartis, Pfizer, SUN, and UCB, Grant/research support from: AbbVie, Amgen Bristol Myers Squibb, Eli Lilly, Galapagos, Gilead, Janssen, Novartis, Pfizer, SUN, and UCB, Peter Foley Speakers bureau: AbbVie, Celgene, Janssen, Lilly, Merck, Novartis, Pfizer, Valeant, Galderma, GSK, Leo Pharma, and Roche, Consultant of: Janssen, Lilly, Novartis, Pfizer, Galderma, AbbVie, Amgen, AstraZeneca, Arcutis Aslan, Boehringer Ingelheim, Celgene, Hexima, Merck, Sun Pharma, UCB Pharma, Valeant, BMS, Celtaxsys, CSL, Cutanea, Dermira, Genentech, GSK, Leo Pharma, Regeneron Pharmaceuticals Inc, Reistone, Roche, and Sanofi, Grant/research support from: AbbVie, Amgen, Celgene, Janssen, Leo Pharma, Lilly, Merck, Novartis, Pfizer, Sanofi, and Sun Pharma; travel grants from AbbVie, Janssen, Lilly, Merck, Novartis, Pfizer, Galderma, Leo Pharma, Roche, Sun Pharma, and Sanofi

, Kristian Reich Consultant of: AbbVie, Amgen, Gilead, Janssen, Lilly, Novartis, Pfizer, and UCB Pharma, Grant/research support from: AbbVie, Amgen, and UCB Pharma, Jerry Bagel Speakers bureau: AbbVie, Celgene Corporation, Eli Lilly, Janssen Biotech, and Novartis, Consultant of: AbbVie, Amgen, Celgene Corporation, El Lilly and Company, Janssen Biotech, Leo Pharma, Novartis, Sun Pharmaceutical 